\title{
Sclerosing encapsulating peritonitis: a case report*
}

Peritonite esclerosante encapsulante: relato de caso

\section{Paula de Castro Menezes Candido ${ }^{1}$, Andrea de Freitas Werner $^{2}$, Izabela Machado Flores Pereira ${ }^{3}$, Breno Assunção Matos ${ }^{3}$, Rudolf Moreira Pfeilsticker ${ }^{4}$, Raul Silva Filho ${ }^{4}$}

Candido PCM, Werner AF, Pereira IMF, Matos BA, Pfeilsticker RM, Silva Filho R. Sclerosing encapsulating peritonitis: a case report. Radiol Bras. 2015 $\mathrm{Jan} / \mathrm{Fev} ; 48(1): 56-58$.

Abstract Sclerosing encapsulating peritonitis, a rare cause of bowel obstruction, was described as a complication associated with peritoneal dialysis which is much feared because of its severity. The authors report a case where radiological findings in association with clinical symptoms have allowed for a noninvasive diagnosis of sclerosing encapsulating peritonitis, emphasizing the high sensitivity and specificity of computed tomography to demonstrate the characteristic findings of such a condition.

Keywords: Sclerosing encapsulating peritonitis; Peritoneal dialysis; Peritoneal fibrosis; Intestinal obstruction; Computed tomography; Chronic renal failure.

Res u mo Peritonite esclerosante encapsulante, causa rara de obstrução intestinal, foi descrita como uma complicação associada à diálise peritoneal, muito temida por sua gravidade. Relata-se um caso em que os achados radiológicos associados aos sintomas clínicos permitiram o diagnóstico não invasivo de peritonite esclerosante encapsulante, destacando-se a alta sensibilidade e especificidade da tomografia computadorizada na demonstração dos achados característicos.

Unitermos: Peritonite esclerosante encapsulante; Diálise peritoneal; Fibrose peritoneal; Obstrução intestinal; Tomografia computadorizada; Insuficiência renal crônica.

\section{INTRODUCTION}

Sclerosing encapsulating peritonitis is a rare cause of bowel obstruction and is characterized by the presence of a thick fibrotic membrane partially or completely involving the small bowel ${ }^{(1)}$. This condition was described as a disease associated with peritoneal dialysis in 1978 and, despite its rarity, is a feared complication because of its severity ${ }^{(2)}$.

Radiological findings in association with clinical symptoms allow a noninvasive diagnosis, and computed tomography $(\mathrm{CT})$ is the most sensitive and specific imaging modality to demonstrate characteristic findings ${ }^{(3,4)}$.

\section{CASE REPORT}

A female, 43-year-old patient who had undergone renal transplantation in 2002 with immediate postoperative graft failure, when peritoneal dialysis was initiated. In 2011 , the patient was admitted presenting abdominal pain and distension, decreased in dialytic process efficiency and occasional presence of blood in the dialysis effluent. Abdominal radiography showed subtle linear calcifications in areas of bowel

* Study developed at Hospital Felício Rocho, Belo Horizonte, MG, Brazil.

1. Trainee in Radiology at Hospital Felício Rocho, Belo Horizonte, MG, Brazil.

2. Resident of Radiology at Hospital Felício Rocho, Belo Horizonte, MG, Brazil.

3. Trainees in Radiology at Hospital Felício Rocho, Fellow degrees at Faculdade de Ciências Médicas de Minas Gerais, Belo Horizonte, MG, Brazil.

4. MDs, Radiologists at Hospital Felício Rocho, Belo Horizonte, MG, Brazil.

Mailing address: Dra. Paula de Castro Menezes Candido. Hospital Felício Rocho - Setor de Radiologia. Avenida do Contorno, 9530, Barro Preto. Belo Horizonte, MG, Brazil, 0110-934. E-mail:paulacmcandido@yahoo.com.br.

Received September 5, 2013. Accepted after revision January 22, 2014. loops (Figure 1). CT revealed the presence of gross linear calcifications corresponding to thickening and calcification of intestinal and peritoneal walls in association with distended

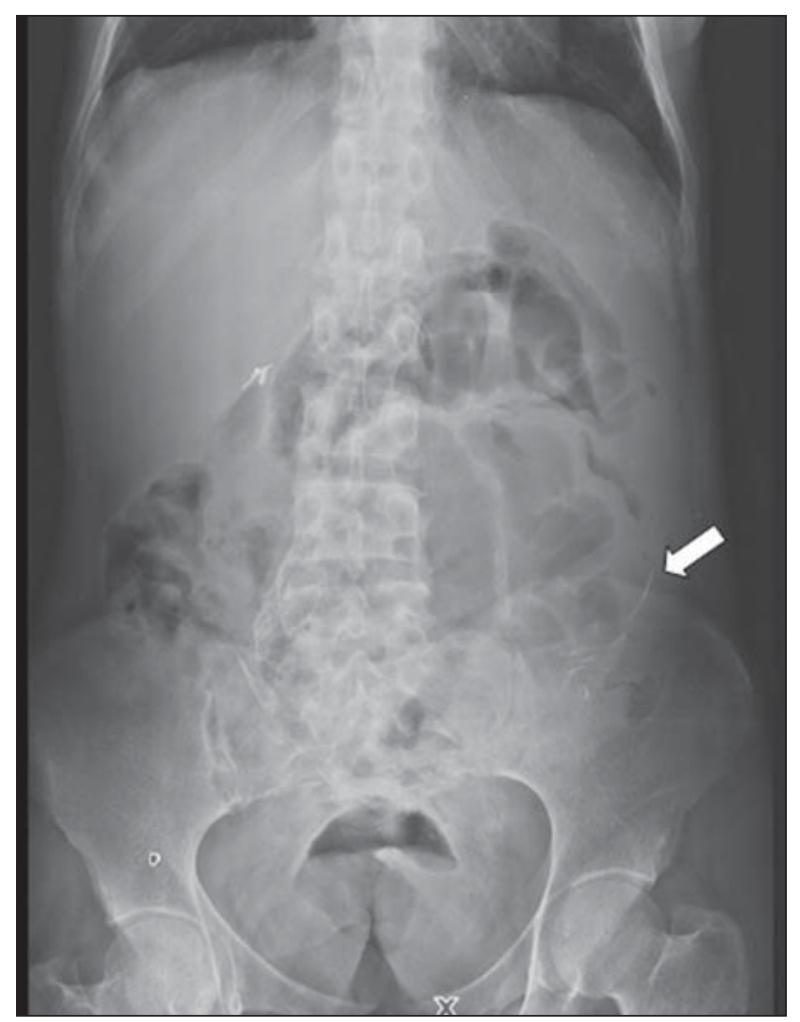

Figure 1. Anteroposterior abdominal radiography demonstrating radiopaque, elongated structures in the region of the bowel loops (arrow) and gaseous distention of small bowel loop in the center of the abdomen. 
bowel loops with fluid and air contents in the central region of the abdomen (Figures 2, 3 and 4). In 2012, the patient was admitted presenting vomiting, abdominal distension and pain, and underwent surgery, progressing with fistulas, hemodynamic instability and death, with diagnosis of sclerosing encapsulating peritonitis presumed from the classical clinical and radiological findings.

\section{DISCUSSION}

Sclerosing encapsulating peritonitis, described by Owtschinnikow in 1907, is classified into idiopathic or sec-

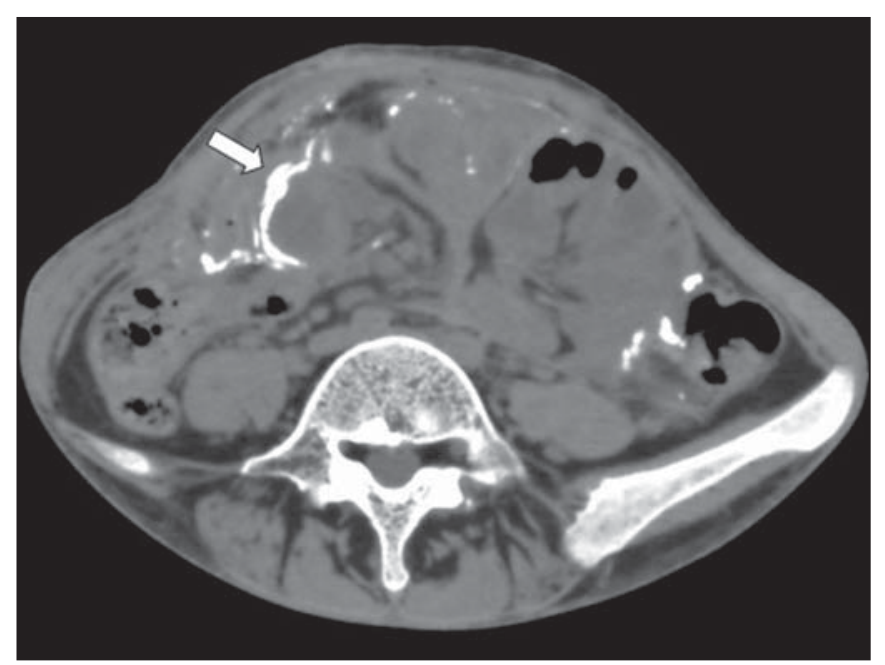

Figure 2. Axial abdominal CT section demonstrating thickening and calcification of intestinal and peritoneal walls (arrow).

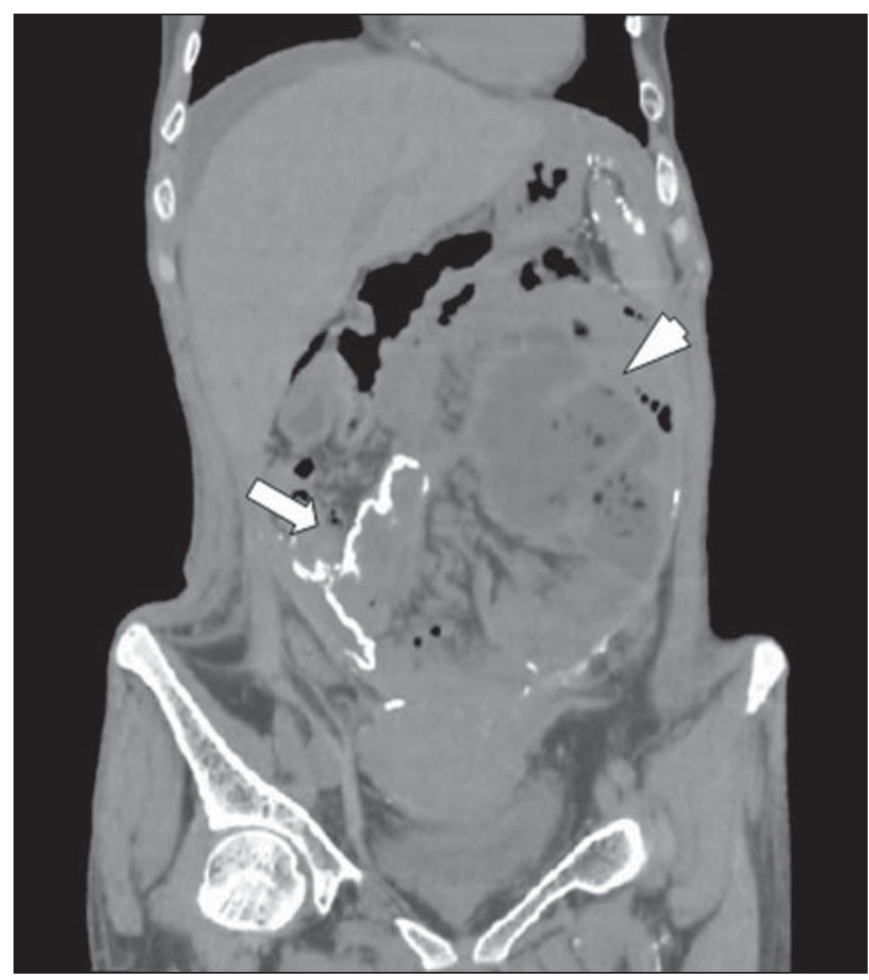

Figure 3. Coronal abdominal CT section presenting gross calcifications in intestinal and peritoneal walls (arrow) and distended bowel loops with fluid and air contents located in the central region of the abdomen (arrowhead).

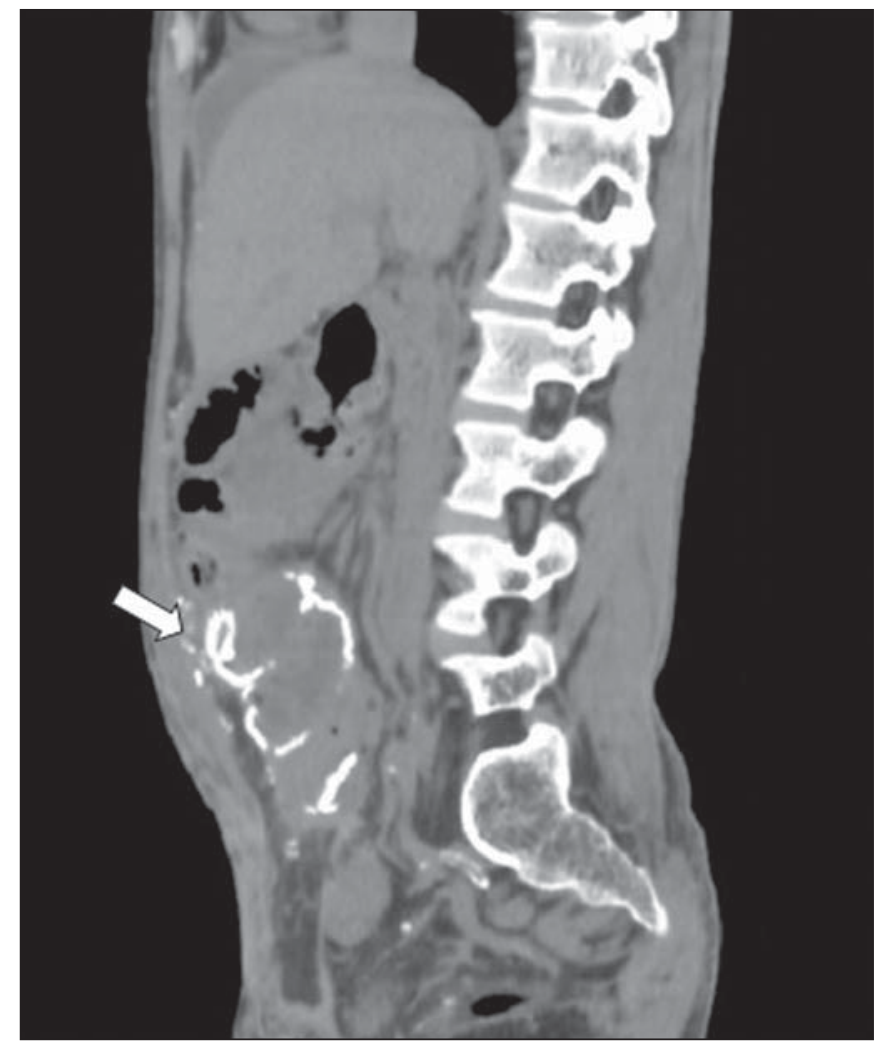

Figure 4. Sagittal abdominal CT section showing thickening and calcification of intestinal and peritoneal walls (arrow). Presence of linear, gross calcifications.

ondary. The secondary presentation has been reported mainly in association with continuous peritoneal dialysis ${ }^{(1)}$.

Peritoneal dialysis is a therapeutic modality for renal failure that presents several advantages. However, its longterm efficacy is limited by complications, from the most common one, such as bacterial peritonitis, to the most severe - sclerosing encapsulating peritonitis -, whose incidence ranges from $0.9 \%$ to $7.3 \%$.

The main potential risk factors for development of sclerosing encapsulating peritonitis are the peritoneal dialysis duration and occurrence of repeated episodes of peritonitis $^{(3,5,6)}$. In spite of the decline in its incidence in the last two decades, due mainly to the utilization of more biocompatible solutions, the survival associated with sclerosing encapsulating peritonitis remains extremely low ${ }^{(4)}$.

The classification system proposed by Kawanishi et al., based on clinical and pathological results, divides sclerosing encapsulating peritonitis into four phases, as follows: presclerosing encapsulating peritonitis, inflammatory phase, progressive phase, and fibrotic phase. Initially, the symptoms are nonspecific (fever, ascites, weight loss, anorexia and bowel habit alteration), indicating the presence of an initial inflammatory process. With the disease progression, ileal symptoms arise $^{(4)}$. If sclerosing encapsulating peritonitis develops even during peritoneal dialysis, signs such as bloody effluents, recurrent peritonitis episodes and ultrafiltration problems may occur. The occurrence of frequent episodes of bowel obstruction indicates the onset of the fibrotic phase ${ }^{(4)}$. 
Although this is a rare complication, bowel obstruction resulting from sclerosing encapsulating peritonitis should be considered in any patient undergoing long-term peritoneal dialysis with recurrent abdominal pain ${ }^{(3)}$. The rate of mortality associated with sclerosing encapsulating peritonitis ranges between $43.5 \%$ and $78 \%$, and depends on the occurrence of complications ${ }^{(2)}$, such as partial or complete small bowel obstruction, small bowel necrosis and enterocutaneous fistulas, which require surgical intervention, with high mortality $^{(3)}$.

The diagnosis of sclerosing encapsulating peritonitis has been based on the International Society of Peritoneal Dialysis guidelines established in 2005, whose key criteria include presence of ileal obstruction symptoms either with or without systemic inflammatory reaction, in association with characteristic findings at the radiological investigation ${ }^{(7)}$.

Radiological findings associated with clinical symptoms constitute a noninvasive method to confirm such condition ${ }^{(4)}$. Amongst the available techniques, CT is the most sensitive and specific to demonstrate characteristic findings ${ }^{(3,4)}$ including peritoneal thickening $(100 \%)$, calcifications $(70 \%)$, peritoneal enhancement (50\%), congregated small bowel loops in the center of the abdomen $(60 \%)$ and loculated fluid collections $(90 \%)^{(3-5)}$. Despite the diagnostic value of CT, was verified that it is not very useful as a screening method.

Other imaging methods such as abdominal radiography can also aid in the diagnosis demonstrating findings similar to those observed in the present case ${ }^{(2,5)}$; also, barium contrast study reveals distended loops with decreased and disordered peristalsis $^{(2,5)}$ and ultrasonography identifies loculated ascites $^{(1,2)}$ and a characteristic, uniformly echogenic previsceral membrane anterior to the bowel loops ${ }^{(5)}$. The role played by magnetic resonance imaging is currently being evaluated, but preliminary data suggest results similar to the ones of $\mathrm{CT}^{(8)}$.

As regards the treatment, the therapeutic approach depends on the stage of the disease ${ }^{(2)}$. Several treatments have been proposed, including pharmacological and surgical options, the latter being required in cases of bowel obstruction $^{(1-8)}$. Symptoms recurrence occurs in up to $25 \%$ of patients, generally within 12 to 24 months ${ }^{(4)}$.

\section{REFERENCES}

1. Xu P, Chen LH, Li YM. Idiopathic sclerosing encapsulating peritonitis (or abdominal cocoon): a report of 5 cases. World J Gastroenterol. 2007;13:3649-51

2. Machado DJB, Romão Jr JE, Sabbaga E, et al. Peritonite esclerosante e encapsulante secundária à diálise peritoneal ambulatorial contínua. J Bras Nefrol. 1999;21:112-23.

3. Choi JH, Kim JH, Kim JJ, et al. Large bowel obstruction caused by sclerosing peritonitis: contrast-enhanced CT findings. Br J Radiol. 2004;77:344-6.

4. Bargman J, Harel Z. Encapsulating peritoneal sclerosis. US Nephrol. 2011;5:71-5.

5. Stuart S, Booth TC, Cash CJC, et al. Complications of continuous ambulatory peritoneal dialysis. Radiographics. 2009;29:441-60.

6. Habib AM, Preston E, Davenport A. Risk factors for developing encapsulating peritoneal sclerosis in the icodextrin era of peritoneal dialysis prescription. Nephrol Dial Transplant. 2010;25:1633-8.

7. Kawanishi H, Moriishi M. Encapsulating peritoneal sclerosis: prevention and treatment. Perit Dial Int. 2007;27 Suppl 2:S289-92.

8. Guest S. Hypothesis: gender and encapsulating peritoneal sclerosis. Perit Dial Int. 2009;29:489-91. 